\title{
Publisher Correction: Pore elimination mechanisms during 3D printing of metals
}

S. Mohammad H. Hojjatzadeh (1) 1,2, Niranjan D. Parab (1) ${ }^{3}$, Wentao Yan (1) 4, Qilin Guo (1) 1,2, Lianghua Xiong (1) 1,2, Cang Zhao (10 ${ }^{3}$, Minglei Qu (1) 1,2, Luis I. Escano ${ }^{1}$, Xianghui Xiao (D) ${ }^{3}$, Kamel Fezzaa (1) ${ }^{3}$, Wes Everhart (iD) ${ }^{5}$, Tao Sun (i) ${ }^{3 \star} \&$ Lianyi Chen (i) ${ }^{1,2 \star}$

Correction to: Nature Communications https://doi.org/10.1038/s41467-019-10973-9, published online 12 July 2019.

The original version of this Article contained an error in Fig. 4. The $x$-axis labels in Fig. 4a, b were incorrectly labelled 'Diameter (mm)', rather than the correct 'Diameter $(\mu \mathrm{m})$ '. This has been corrected in both the PDF and HTML versions of the Article.

Published online: 30 September 2019

\begin{abstract}
(c) (i) Open Access This article is licensed under a Creative Commons Attribution 4.0 International License, which permits use, sharing, adaptation, distribution and reproduction in any medium or format, as long as you give appropriate credit to the original author(s) and the source, provide a link to the Creative Commons license, and indicate if changes were made. The images or other third party material in this article are included in the article's Creative Commons license, unless indicated otherwise in a credit line to the material. If material is not included in the article's Creative Commons license and your intended use is not permitted by statutory regulation or exceeds the permitted use, you will need to obtain permission directly from the copyright holder. To view a copy of this license, visit http://creativecommons.org/licenses/by/4.0/.
\end{abstract}

(C) The Author(s) 2019

\footnotetext{
${ }^{1}$ Department of Mechanical and Aerospace Engineering, Missouri University of Science and Technology, Rolla, MO 65409, USA. ${ }^{2}$ Department of Materials Science and Engineering, Missouri University of Science and Technology, Rolla, MO 65409, USA. ${ }^{3}$ X-ray Science Division, Advanced Photon Source, Argonne National Laboratory, Lemont, IL 60439, USA. ${ }^{4}$ Department of Mechanical Engineering, National University of Singapore, Singapore 117575, Singapore. ${ }^{5}$ Department of Energy's Kansas City National Security Campus Managed by Honeywell FM\&T, Kansas City, MO 64147, USA.

*email: taosun@aps.anl.gov or chenliany@mst.edu
} 